\title{
The Effectiveness of a Nondiet Multidisciplinary Weight Reduction Program for Severe Overweight Patients with Psychological Comorbidities
}

\author{
Bettina Bannert, ${ }^{1,2}$ Wolfgang Schobersberger, ${ }^{3}$ Ulrich Tran, ${ }^{4}$ and Andreas Remmel ${ }^{1,4}$ \\ ${ }^{1}$ Psychosomatisches Zentrum Waldviertel (PSZW), Grafenbergerstraße 2, 3730 Eggenburg, Austria \\ ${ }^{2}$ Private University for Health Sciences, Medical Informatics and Technology (UMIT), Eduard Wallnöfer-Zentrum1, \\ 6060 Hall in Triol, Austria \\ ${ }^{3}$ Institute for Sports Medicine, Alpine Medicine and Health Tourism, Private University for Health Sciences, \\ Medical Informatics and Technology (UMIT), Eduard Wallnöfer-Zentrum1, 6060 Hall in Tirol, Austria \\ ${ }^{4}$ Eggenburg Institute for Complex Systems, Health and Neuroscience (EICoN), Grätzl 5, 3730 Eggenburg, Austria
}

Correspondence should be addressed to Wolfgang Schobersberger, wolfgang.schobersberger@uki.at

Received 29 June 2011; Accepted 1 August 2011

Academic Editor: Francesco Saverio Papadia

Copyright (C) 2011 Bettina Bannert et al. This is an open access article distributed under the Creative Commons Attribution License, which permits unrestricted use, distribution, and reproduction in any medium, provided the original work is properly cited.

\begin{abstract}
Objective. For successful sustainable weight reduction, a multimodal program including behaviour therapy is needed. Lifestyle modification is mostly used for obesity BMI $<40 \mathrm{~kg} / \mathrm{m}^{2}$. The present study demonstrated the effect of an in-patient nondiet lifestyle program for patients with BMI $>40 \mathrm{~kg} / \mathrm{m}^{2}$ with psychological comorbidity. Research Methods and Procedere. A retrospective data analysis of 99 participants who passed the program based on moderate activity, healthy and regular food intake over metabolic rate and behaviour therapy was conducted. Results. 64 had a BMI $>40 \mathrm{~kg} / \mathrm{m}^{2}$ (mean value $49.99 \pm 8.74$ ). The relative weight reduction was $-6.9 \pm 3.9 \%$; (Friedman test $P<0.05$ ). Binary logistic regression analysis for $n=79$ revealed that the achievement of the weight reduction goal ( $0.5 \mathrm{~kg}$ per week; predictors: sex, incidence of MTS, duration of in-patient therapy, psychological symptoms, BMI and activity level at baseline $)$ was associated with a shorter duration of in-patient therapy $(P=0.007)$ and higher BMI at baseline $(P=0.010)$. Conclusion. Participants with BMI $>40 \mathrm{~kg} / \mathrm{m}^{2}$ may achieve significant changes of weight reduction and psychological symptoms. However, the primary outcome should not be weight reduction. It is necessary to identify the benefits of lifestyle modification on changing risk profiles and emotional regulation of food intake.
\end{abstract}

\section{Introduction}

Worldwide, already 1 billion people are overweight and more than 300 million are obese [1,2]. Particularly, the increase in extremely overweight people was recently demonstrated $\left(\mathrm{BMI} \geq 40 \mathrm{~kg} / \mathrm{m}^{2}\right)[1]$. In the USA, already the prevalence of $4.8 \%$ in this group has been recorded [2].

Obesity is the result of a long-term positive energy balance, caused by lack of exercise combined with hypercaloric nutrition $[3,4]$. An effective therapy for this multifactor health problem is the combination of multiple therapy facilities [5]. Also for a successful long-term effect, a multimodal treatment [5-7] aimed at the motivation of the obese patient for lifestyle modification is essential. Increasing physical activity and diet are important for an effective weight management [8].

However, a varied mixing food with the reference value of the basal metabolism is to be preferred for the effectiveness of changing the food pattern because there is often a resulting nutrient deficiency and the risk of drop-outs [7].

The role of activity producing a long-term effect in weight loss is well documented $[9,10]$. But, there exists no consistent recommendation how much activity is enough to have the best effect. But, a higher duration of activity, such 
as more than $200 \mathrm{~min} /$ week $(P<0.001)$, is more effective to produce greater weight loss [11]. This finding implicates a higher duration of activity than recommended $[5,12,13]$.

Energy expenditure produced by physical activity and the food intake must result in a daily energy deficit of minimum $500 \mathrm{kcal}[9]$.

Lifestyle modification in the context of more activity is the key point for successful weight management, as reported in earlier studies [11-14]. However, the description of the amount of activity varies and there are no reported profits for the patients with regards to quality of life. There is also lack of standardized definition about lifestyle intervention [15-19]. Whereas the usual kinds of lifestyle modification are mostly used for obesity close to BMI $40 \mathrm{~kg} / \mathrm{m}^{2}$ [20], patients with a BMI over $50 \mathrm{~kg} / \mathrm{m}^{2}$ should also start with a combined therapy in an in-patient setting $[7,21]$.

Obesity is linked to major depression disorders. Pagoto et al. [22] reported on 131 subjects with an average BMI of 43.1 that $17 \%$ were depressive, diagnosed via clinical interview (addressing DSM-IV criteria). The often discussed comorbidity of depression as a barrier to change of behaviour is approached by Schneider et al. [23]. So, the success is currently optimized with related behavioural-therapeutic elements [5] for motivation and stabilisation [24].

We hypothesized that an in-patient multidisciplinary nondiet weight reduction program has effectiveness for patients with a BMI $>40 \mathrm{~kg} / \mathrm{m}^{2}$ and psychological comorbidities. In detail, we assumed that patients with a BMI $>40 \mathrm{~kg} / \mathrm{m}^{2}$ can lose $5 \%$ of their initial weight with an inpatient multidisciplinary nondiet weight reduction program.

\section{Method}

2.1. Participants. 198 patients with a BMI $>30 \mathrm{~kg} / \mathrm{m}^{2}$ and psychological comorbidities finished a multidisciplinary inpatient nondiet weight reduction program between February 2007 and August 2010. In consideration of the exclusion and inclusion criteria (Table 1), 99 patients could be considered in a pre/postanalysis. To evaluate the effect of the program, a followup after 3, 6, and 9 month posttreatment was conducted. The in-patient treatment took 8 to 12 weeks with a structured week timetable.

2.2. Treatment. All group interventions were not constructive on each other because of the open-group situation. Activities like aqua gymnastic, walking, or a condition and coordination training (aerobic low impact and elements of resistance training using the own bodyweight), elements of relaxation, and body awareness as well as behaviouraltherapeutic elements of motivation, stabilisation, and emotional regulation in group and individual settings for optimizing the success [5] were included. The activities were composed that the patients could integrate them in the daily routine. The behavioural therapy is taking place in group interventions and two individual calls. For the regulation of emotions, the research group have integrated a Skillstraining once a week.

This extensive program is developed since January 2007 and the interventions are shown in Table 2.
Objective and subjective parameters were measured preand posttreatment. In Table 3, the parameters and their instruments of assessment are shown.

2.3. Measures. To evaluate the HRQL, the generic instrument-Short Form-36 (SF-36), a valid self-administered questionnaire [25]—was used. For the impact of psychological symptoms, also a self-reported questionnaire, the SCL-90 R (symptom Check list), was used [26]. Eating habits were assessed with a 3 factor-eating questionnaire FEV [27]. Body composition was measured with a bioimpedance analysis instrument (DATA INPUT Nutriguard-M). Food intake and activity were assessed with questionnaires of the validated "Schlank ohne Diät" (SOD, lean without diet) program [28]. For height, weight, and the waist circumference, standardized instruments were applied.

2.4. Statistical Analysis. For analysis, PASW statistics 18 was used. The objective parameter and dependent variable weight reduction was standardized with respect to an intended 5\% weight reduction goal. Due to the nonGaussian distribution of the data, tested with the Kolmogorow-Smirnow test, nonparametric tests (Wilcoxon test, Friedman test) were used for pre/postanalyses. The statistical significance was set at $P<0.05$ (two tailed). For parameter estimates, 95\% confidence intervals were also computed. Binary logistic regression was used to identify predictors of achieving the weight reduction goal. Independent variables were based on previous findings: duration of the in-patient therapy [29], sex, age, BMI [30], the psychological symptoms (GSI) [23], and the baseline fitlevel $[11,13]$.

In consideration of the aim of this study, the sample was also split into participants with BMI $<40 \mathrm{~kg} / \mathrm{m}^{2}$ and BMI $>40 \mathrm{~kg} / \mathrm{m}^{2}$.

\section{Results}

3.1. Sample. Data from 99 participants were obtained from medical records retrospectively.

$68(68.7 \%)$ women and $31(31.3 \%)$ men with the mean age of $43.79 \pm 12.44\left(\right.$ o $\left.44.12 \pm 12.56 ; \sigma^{7} 43.06 \pm 12.36\right)$ were analysed. The BMI at baseline was $44.96 \pm 9.93$ (ㅇ $44.31 \pm$ $\left.9.61 ; \sigma^{7} 46.38 \pm 10.61\right)$. The duration of therapy was $71.39 \pm$ 16.2 days.

In consideration of the aim of the study to identify the effectiveness of a nondiet multidisciplinary weight reduction program, we focused on the subgroup with a BMI $>40 \mathrm{~kg} / \mathrm{m}^{2}$. Sixty-four participants had a BMI $>40 \mathrm{~kg} / \mathrm{m}^{2}$ (mean value $49.99 \pm 8.74)$ and were included for further analysis. The mean age was $43.76 \pm 12.45$ years. $43(67.2 \%)$ participants were women. The duration of in-patient therapy was $75.33 \pm$ 14.897. Thirty of the 64 participants $(46.9 \%)$ had a metabolic syndrome.

The mean load of psychological symptoms at baseline was $0.95 \pm 0.65$ and the subjective fitlevel was $21.83 \pm 15.57$. Objective parameters like body fat were at baseline $47.01 \pm$ $7.01 \%$ and the waist circumference $147.18 \pm 20.36 \mathrm{~cm}$ (Table 4). 
TABLE 1: Inclusion and exclusion criteria of the study.

\begin{tabular}{ll}
\hline Exclusion & Inclusion \\
\hline (i) Bulimia nervosa & $\begin{array}{l}\text { (i) Adults with a BMI } \geq 30 \mathrm{~kg} / \mathrm{m}^{2} \text { and psychological } \\
\text { comorbidities classified to ICD-10 criteria }\end{array}$ \\
$\begin{array}{l}\text { (ii) Serious personality disorder } \\
\text { (iii) Schizophrenia }\end{array}$ \\
(iv) Conduct disorders \\
(v) Serious reduction of intelligence \\
(vi) Patients after a myocardial infarct (MCI) and heart insufficiency \\
(NYHA III/IV) \\
(vii) The existence of diabetes mellitus type I \\
(viii) Renal insufficiency \\
(ix) Serious COPD or asthma bronchial \\
(x) Serious hormonal disorders \\
(xi) Tumours \\
(xii) Lactation or pregnancy \\
(xiii) Attendance on another study or weight loss program at the same time \\
(xiiii) Patients with a regularly higher dosed medication known to affect \\
appetite and/or weight like corticosteroid, SHD-hormones, or diuretics \\
which are taken in the last 3 months
\end{tabular}

TABLE 2: Weekly timetable of interventions of the "schwerelos" program.

\begin{tabular}{|c|c|c|}
\hline \multirow{3}{*}{$\begin{array}{l}\text { Medical science: } \\
\text { (i) somatic comorbidities and complications } \\
\text { (ii) medication }\end{array}$} & Medical visits & 2x á 90 min \\
\hline & Surgery hour & $1 \mathrm{x}$ á $60 \min$ \\
\hline & Psychiatric consultation & $1 \mathrm{x}$ á $60 \min$ \\
\hline \multirow{5}{*}{$\begin{array}{l}\text { Psychology: } \\
\text { (i) behaviour } \\
\text { (ii) emotion } \\
\text { (iii) cognition } \\
\text { (iv) motivation }\end{array}$} & Individual therapy & $2 \mathrm{x}$ á 50 min \\
\hline & Group intervention & $2 \mathrm{x}$ á $60 \min$ \\
\hline & Skills and social competence training & each $2 x$ á 60 min \\
\hline & Self-image & 1x á 60 min \\
\hline & Relaxation & $1 \mathrm{x}$ á 60 min \\
\hline $\begin{array}{l}\text { Nutrition: } \\
\text { (i) balanced meal (food guide pyramid) }\end{array}$ & Nutrition information & $2 \mathrm{x}$ á $60 \mathrm{~min}$ \\
\hline (ii) food pattern, typus of food intake & Individual counseling & $1 \mathrm{x}$ á 60 min \\
\hline \multirow{3}{*}{$\begin{array}{l}\text { Activity: } \\
\text { (i) cardiotraining } \\
\text { (ii) strengthendurance }\end{array}$} & Aqua-gymnastic & 2x á 30 min \\
\hline & Music-gymnastic/low-impact & $2 \mathrm{x}$ á $30 \mathrm{~min}$ \\
\hline & Walking & 2x á 30 min \\
\hline
\end{tabular}

With the exception of triglycerides, LDL-cholesterol, and alexithymia from TAS 26, differences of all other measured parameters $(t 1$ versus $t 2)$ were significant $(P<0.05)$ (Table 5).

The relative weight reduction of the BMI $>40 \mathrm{~kg} / \mathrm{m}^{2}$ subgroup was $\varnothing-6.9 \pm 3.9 \%$. The standardized weight ( $5 \%$ weight reduction goal) for both subgroups is shown in Figure 1. Weight reduction over time was significant for both groups $(P<0.001)$ with a significant group difference $(z=-2.606 ; P=0.009)$ at posttreatment. On average, both groups achieved the $5 \%$ weight goal after intervention, patients with a BMI $>40 \mathrm{~kg} / \mathrm{m}^{2}$ already at week eight. 42 of $64(65.6 \%)$ patients with BMI $>40 \mathrm{~kg} / \mathrm{m}^{2}$ achieved the $5 \%$ weight reduction goal.

The relative weight reduction and changes in the somatoform dimension of the SCL-90 R, the dimension body pain of the SF-36, \% body fat, and waist circumference were significant (Spearman correlation $P<0.05$; Table 6).

We conducted a binary logistic regression analysis including also the patients with BMI $<40 \mathrm{~kg} / \mathrm{m}^{2}$ (total $n=$ 79) regarding the achievement of the weekly weight reduction goal of a loss of $0.5 \mathrm{~kg}$ in average per week [28] to test whether patients with BMI $>40 \mathrm{~kg} / \mathrm{m}^{2}$ and patients with $\mathrm{BMI}<40 \mathrm{~kg} / \mathrm{m}^{2}$ differed significantly in treatment outcomes. Predictors were participant, sex, incidence of the metabolic syndrome, duration of the in-patient therapy, BMI, waist circumference, and subjective activity level at baseline. Selected variables were significant in correlation with weight reduction $(P<0.05)$. The psychological symptoms (GSI) were included in the model as a control variable $(r=-0.19)$.

The chi-square test of the full model with all seven predictors was significant $\left(n=79, \chi^{2}=25.25, \mathrm{df}=7\right.$, 
TABLE 3: Parameters and methods of assessment.

\begin{tabular}{lc}
\hline Parameter & Method \\
\hline Anthropometric: & \\
Height, weight — BMI & Scale, chain, $\mathrm{kg} / \mathrm{m}^{2}$ \\
Waist circumference & BIA \\
Body composition & \\
Blood Serum: & Haemogram \\
Cholesterol/LDL-C & \\
Triglyceride & FEV \\
Nutrition: & Recall (SOD) \\
Nutrition behaviour & \\
Food intake & SCL-90-R \\
Psychological Symptoms and Well-Being: & SF-36 \\
Depression/psychological symptoms & \\
Health related quality of life (HRQL) & SOD \\
Activity: & Fitlevel
\end{tabular}

In-patient development of weight, standardized on $-5 \%$ from initial weight divided to $\mathrm{BMI}<40 \mathrm{~kg} / \mathrm{m}^{2}(n=35)$ and $\mathrm{BMI}>40 \mathrm{~kg} / \mathrm{m}^{2}(n=64)$

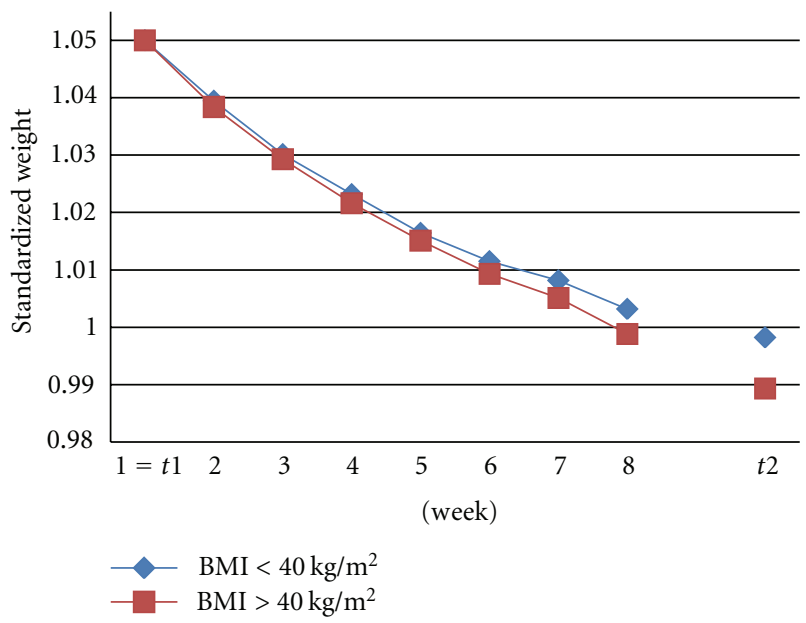

FIGURE 1: In-patient body weight of the subgroups BMI $\lessgtr 40 \mathrm{~kg} / \mathrm{m}^{2}$.

$P=0.001$ ). Model-based classifications (cut-off of 0.5 ) were correct in $55 \%$ of the cases for goal not attained and in $94.9 \%$ of cases for goal attained. The overall rate of correct classifications was $84.8 \%$. Nagelkerkes $R^{2}$, as the equivalent for the proportion of the variance of the criterion explained by the predictors, was $40.9 \%$. The Hosmer-Lemeshow test was not significant $(P=0.763)$.

Duration of an in-patient therapy $(P=0.007)$ and the BMI at baseline $(P=0.01)$ were significant predictors to attain the weight reduction goal, and a trend for the fitlevel at baseline $(P=0.089)$ was identified (Table 7$)$. The odds ratio of the duration of in-patient therapy and the fitlevel at baseline $(\mathrm{OR}<1)$ demonstrated that a higher subjective estimate of activity and also a longer hospital stay were associated with a lower probability of achieving the weight reduction goal.
Long-term outcomes (1-year followup) were available for only 23 patients, $17(73.9 \%)$ of which had a baseline BMI $>40 \mathrm{~kg} / \mathrm{m}^{2}$. Twelve $(70.6 \%)$ of these 17 patients achieved and maintained a weight reduction goal of $5-10 \%$ of their initial weight. There was a little difference between participants who make a regular use of the 3 monthly checks $(n=13)$ including also a psychological interview beside the measures of the objective and subjective parameters, to them, who came irregular to the check $(n=10)$.

\section{Discussion}

The aim of the study was to demonstrate the achievement of weight reduction in the subgroup BMI $>40 \mathrm{~kg} / \mathrm{m}^{2}$ with psychological comorbidities with a multimodal nondiet inpatient weight reduction program.

The most interesting finding of the presented study was a significant weight loss over time $(P<0.001)$ with a group difference to $\mathrm{BMI}<40 \mathrm{~kg} / \mathrm{m}^{2}(P<0.05)$. While there were significant changes in most of the subjective and objective parameters, there were only a few psychological parameters in the subgroup BMI $>40 \mathrm{~kg} / \mathrm{m}^{2}$ correlated with weight reduction (somatoform dimension of the SCL-90 R; $r=-0.316$ and the subscale pain of SF-36; $r=0.441)$. Findings of this study in this heterogenic field of obese patients with the psychological comorbidity are consistent with past studies [22, 31, 32]. Psychological comorbidities were associated with less weight loss as reported by Pagoto et al. [22]. Whereas $16 \%$ of patients with major depression achieved a weight reduction goal of $\geq 7 \%, 38 \%$ of the nondepressed patients did it [22]. Comparable to Carroll et al. [31] improvements in cholesterol, waist circumference, and \% body fat $(P<0.05)$ as parameters of the metabolic syndrome were demonstrated. Also there was no relevant correlations between weight reduction and psychological variables reported [31]. Equivalent to De Zwaan et al., analysis had identified no relationship between a higher BMI and mental health [32]. So, patients with a BMI $>40 \mathrm{~kg} / \mathrm{m}^{2}$ had no significant group difference to a lower BMI in respect of the general symptomatic index $(F=0.63 ; P=0.803)$. Also weight reduction was not related to PCS $(r=0.172)$ and MCS $(r=0.094)$ of the SF-36.

The relative weight reduction was higher (mean value $-6.9 \pm 3.9 \%$ ) than in the group BMI $<40 \mathrm{~kg} / \mathrm{m}^{2}$ (mean value $-4.9 \pm 2.4 \%)$ [33]. Goodpaster et al. [33] demonstrated equivalent results of weight loss at patients with BMI $>40 \mathrm{~kg} / \mathrm{m}^{2}$ compared with lower BMI (10.9\% versus $7 \%$ at 12 months). But, there was a high variability in both groups at the presented study. While the goal of the $0.5 \mathrm{~kg}$ each week [28] was achieved by 52 participants (81.3\%), 42 of the $64(65.6 \%)$ participants in this group obtained also the successful weight loss, defined as $\geq 5 \%$ from initial weight at 1 -year followup $[5,13]$. This value is evident for reducing the risk of cardiovascular diseases [34-36]. As already abovementioned parameters of the metabolic syndrome that decreased significantly $(P<0.05)$, there were also positive effects without weight reduction [35]. Body composition is one of the most interesting parameters demonstrating the improvement of risk profile. Improvements could be shown 
TABLE 4: Descriptive statistic of patients with BMI $\lessgtr 40 \mathrm{~kg} / \mathrm{m}^{2}$.

\begin{tabular}{|c|c|c|c|c|c|c|c|c|c|}
\hline & $N$ & Mean value & S.E. & $\begin{array}{c}N \\
\mathrm{BMI}>40 \mathrm{~kg} / \mathrm{m}^{2}\end{array}$ & Mean value & S.E. & $\begin{array}{c}N \\
\mathrm{BMI}<40 \mathrm{~kg} / \mathrm{m}^{2}\end{array}$ & Mean value & S.E. \\
\hline Age (years) & 99 & 43,79 & 12,44 & 64 & 43,76 & 12,45 & 35 & 43,83 & 12,61 \\
\hline Weight (kg) & 99 & 129,60 & 35,49 & 64 & 143,29 & 35,69 & 35 & 104,56 & 16,54 \\
\hline BMI $\left(\mathrm{kg} / \mathrm{m}^{2}\right)$ & 99 & 44,96 & 9,93 & 64 & 49,99 & 8,75 & 35 & 35,76 & 2,75 \\
\hline Waist circumference $(\mathrm{cm})$ & 98 & 136,53 & 22,75 & 63 & 147,18 & 20,36 & 35 & 117,37 & 11,52 \\
\hline Body fat $(\%)$ & 98 & 44,72 & 7,28 & 63 & 47,01 & 7,01 & 35 & 40,61 & 5,86 \\
\hline GSI & 97 & ,9432 & ,62 & 64 & ,95 & ,65 & 33 & ,9212 &, 56 \\
\hline Fitlevel & 80 & 24,74 & 15,67 & 54 & 21,83 & 15,58 & 26 & 30,77 & 14,35 \\
\hline Weight reduction in $\%$ & 93 & $-6,01$ & 3,38 & 59 & $-6,63$ & 3,69 & 34 & $-4,95$ & 2,47 \\
\hline Duration in-patient therapy (days) & 99 & 71,39 & 16,20 & 64 & 75,33 & 14,9 & 35 & 64,20 & 16,21 \\
\hline
\end{tabular}

TABle 5: Descriptive statistics of the subgroup BMI $>40 \mathrm{~kg} / \mathrm{m}^{2}$.

\begin{tabular}{|c|c|c|c|c|c|c|c|c|c|c|}
\hline \multirow{2}{*}{ Descriptive statistic $n=64$} & \multicolumn{5}{|c|}{$t 1$} & \multicolumn{5}{|c|}{$t 2$} \\
\hline & $N$ & $\min$ & $\max$ & Mean value & S.E. & $N$ & $\min$ & $\max$ & Mean value & S.E. \\
\hline \multicolumn{11}{|l|}{ Psychological parameters } \\
\hline BDI & 58 & 0 & 38 & 19,01 & 9,55 & 52 & 0 & 34 & $9,97 * *$ & 7,56 \\
\hline SCL90R somatoform dimension & 64 & 1 & 36 & 12,20 & 9,33 & 61 & 0 & 35 & $8,28^{* *}$ & 8,56 \\
\hline SCL90R depressive dimension & 64 & 0 & 47 & 16,12 & 11,48 & 61 & 0 & 41 & $8,7^{* *}$ & 8,76 \\
\hline SCL90R general symptomatic index (GSI) & 64 & 0,02 & 3,39 & 0,95 & 0,65 & 61 & 0 & 2,89 & $0,58^{* *}$ & 0,52 \\
\hline IIPD & 64 & 0,41 & 2,8 & 1,71 & 0,47 & 61 & 0,09 & 2,64 & $1,40^{* *}$ & 0,55 \\
\hline TAS26 & 37 & 25 & 63 & 46,09 & 9,99 & 35 & 30 & 69 & 45,97 & 10,03 \\
\hline \multicolumn{11}{|l|}{ Eating habits } \\
\hline FEV_cognitive restraint & 33 & 1 & 15 & 7,18 & 3,74 & 31 & 1 & 20 & $12,16^{* *}$ & 5,33 \\
\hline FEV_uncontrolled eating & 33 & 1 & 16 & 10,24 & 3,75 & 31 & 1 & 15 & $6,55^{* *}$ & 3,86 \\
\hline Fitlevel & 54 & 0 & 58 & 21,83 & 15,58 & 50 & 8 & 99 & $65,28^{* *}$ & 16,63 \\
\hline \multicolumn{11}{|l|}{ Health related quality of life } \\
\hline SF36 physical functioning & 37 & 5 & 95 & 46,38 & 23,98 & 35 & 0 & 100 & $62,86^{* *}$ & 26,13 \\
\hline SF36 physical role limitation & 37 & 0 & 100 & 29,28 & 36,57 & 35 & 0 & 100 & $56,91^{* *}$ & 43,04 \\
\hline SF36 pain & 37 & 0 & 100 & 48,34 & 28,12 & 35 & 12 & 100 & $62,59 * *$ & 27,48 \\
\hline SF36 general health & 37 & 19 & 92 & 50,28 & 17,11 & 35 & 25 & 97 & $63,69 * *$ & 19,09 \\
\hline SF36 vitality & 37 & 5 & 80 & 34,32 & 17,13 & 35 & 15 & 100 & $58,29 * *$ & 19,81 \\
\hline SF36 social functioning & 37 & 0 & 100 & 54,05 & 27,01 & 35 & 12,5 & 100 & $68,93^{* *}$ & 27,35 \\
\hline SF36 emotional role limitation & 37 & 0 & 100 & 39,64 & 39,16 & 35 & 0 & 100 & $66,67 * *$ & 45,01 \\
\hline SF36 mental health & 37 & 12 & 100 & 55,24 & 19,09 & 35 & 24 & 100 & $66,86^{* *}$ & 19,00 \\
\hline SF36 physical summary score (PCS) & 37 & 15 & 52 & 35,72 & 10,00 & 35 & 15,2 & 56,3 & $42,51^{* *}$ & 10,56 \\
\hline SF36 mental summary score (MCS) & 37 & 20 & 61,7 & 39,68 & 11,53 & 35 & 22,8 & 63,1 & $47,51^{* *}$ & 11,60 \\
\hline \multicolumn{11}{|l|}{ Anthropometric parameters } \\
\hline Weight (kg) & 64 & 104,6 & 322,5 & 143,29 & 35,68 & 64 & 96 & 299 & $133,13^{* *}$ & 32,01 \\
\hline BMI & 64 & 38 & 84 & 49,99 & 8,74 & 61 & 35,1 & 77,8 & $46,43^{* *}$ & 8,01 \\
\hline Waist circumference $(\mathrm{cm})$ & 63 & 115 & 230 & 147,18 & 20,36 & 64 & 112 & 220 & $139,8^{* *}$ & 19,47 \\
\hline$\%$ Body fat & 63 & 28,7 & 60 & 47,01 & 7,01 & 58 & 23,2 & 58,1 & $44,39^{* *}$ & 7,59 \\
\hline \multicolumn{11}{|l|}{ Blood parameters } \\
\hline Cholesterol (mg/dL) & 58 & 126 & 305 & 189,71 & 38,72 & 57 & 118 & 267 & $179,84^{*}$ & 34,81 \\
\hline LDL-cholesterol (mg/dL) & 54 & 48 & 201 & 110,41 & 33,54 & 56 & 40 & 182 & 106,36 & 32,35 \\
\hline Triglycerides (mg/dL) & 58 & 75 & 466 & 166,12 & 76,62 & 57 & 65 & 329 & 159,6 & 57,32 \\
\hline
\end{tabular}

$t 1$ : pre treatment, $t 2$ : posttreatment.

* Correlation is significant at $P<0,05$ (two-tailed).

** Correlation is significant at $P<0,01$ (two-tailed). 
TABLE 6: Spearman correlation matrix of weight reduction and selected variables at BMI $>40 \mathrm{~kg} / \mathrm{m}^{2}$.

\begin{tabular}{lcccccccccc}
\hline Spearman-Rho & $\begin{array}{c}\text { Duration of } \\
\text { in-patient } \\
\text { therapy }\end{array}$ & $\begin{array}{c}\text { General } \\
\text { Symptomatic } \\
\text { Index (GSI) }\end{array}$ & $\begin{array}{c}\text { Somatoform } \\
\text { dimension } \\
\text { SCL-90 R }\end{array}$ & $\begin{array}{c}\text { Depressive } \\
\text { dimension } \\
\text { SCL-90 R }\end{array}$ & $\begin{array}{c}\text { Physical } \\
\text { summary } \\
\text { score SF36 } \\
\text { (PCS) }\end{array}$ & $\begin{array}{c}\text { Mental } \\
\text { summary } \\
\text { score SF 36 } \\
\text { (MCS) }\end{array}$ & $\begin{array}{c}\text { Age } \\
\text { Waist }\end{array}$ & $\begin{array}{c}\text { \% body Fit- } \\
\text { fat } \\
\text { level }\end{array}$ \\
\hline $\begin{array}{l}\text { Weight } \\
\text { reduction }\end{array}$ & $r$ &,- 153 &, 144 &, $316^{*}$ &, 170 &, 172 &, 094 & $-, 083,612^{* *}$ &, $855^{* *}$ &, 160 \\
\hline$* *$ & 64 & 61 & 61 & 61 & 35 & 35 & 64 & 63 & 58 & 50 \\
\hline
\end{tabular}

** Correlation is significant at $P<0,01$ (two-tailed).

* Correlation is significant at $P<0,05$ (two-tailed).

TABLE 7: Variables in the logistic regression model.

\begin{tabular}{|c|c|c|c|c|c|c|}
\hline & \multirow{2}{*}{$B$} & \multirow{2}{*}{ Wald } & \multirow{2}{*}{ Sig. } & \multirow{2}{*}{ OR } & \multicolumn{2}{|c|}{ 95\% C.I. for OR } \\
\hline & & & & & Lower & Upper \\
\hline \multicolumn{7}{|l|}{ Step $1^{\mathrm{a}}$} \\
\hline $\operatorname{Sex}(1)$ &, 84 & 1,06 & ,304 & 2,309 & ,47 & 11,38 \\
\hline MTS (1) &, 03 &, 00 & ,975 & 1,026 &, 21 & 5,09 \\
\hline Age &, 00 &, 01 & 944 & 1,002 & ,94 & 1,07 \\
\hline Duration in-patient therapy &,- 08 & 7,35 &, 007 & ,925 & 87 & ,98 \\
\hline BMI &, 13 & 6,64 &, 010 & 1,143 & 1,03 & 1,27 \\
\hline Fitlevel &,- 04 & 2,89 & 089 & 963 & ,92 & 1,01 \\
\hline GSI &, 24 & ,16 & ,686 & 1,277 & ,39 & 4,18 \\
\hline Constant & 1,68 &, 33 &, 564 & 5,386 & & \\
\hline
\end{tabular}

${ }^{a}$ Variables entered on step 1: sex, metabolic syndrome (MTS), age, duration of in-patient therapy, BMI, fitlevel and general symptomatic index (GSI) at baseline.

independent of weight reduction [9]. Waist circumference is more closely correlated with visceral obesity than the total body fat mass [36], but analysis demonstrated significant changes in both, waist circumference and body fat $(P=$ 0.001). Similar to our findings, Galani and Schneider reported a significant decrease of body weight $(P<0.0001)$, total cholesterol $(P=0.027)$, and waist circumference after lifestyle interventions [36]. So, the focus must be also on evaluation of body composition and blood markers for the metabolic syndrome to identify the benefits of a lifestyle intervention.

We found that a higher duration of in-patient therapy is not significantly correlated with weight reduction $(r=$ 0.153). This finding was different to the study of Beutel et al. [37]. In their equivalent study, a significant correlation of weight loss with a longer in-patient treatment $(r=0.4)$ was demonstrated [37]. In our research, the included participants demonstrated that the $5 \%$ weight reduction goal could be achieved at week eight.

These findings were also defined at the binary logistic regression analysis. The odds ratio of the in-patient stay was 0.925 and consequentially the odds to achieve the weight reduction goal decrease with a longer in-patient therapy. Longer stays in hospital were reported to correlate with a higher load of psychological comorbidity. So, it could be expected that participants with a higher load of psychological symptoms need a longer in-patient therapy. Also interesting was the subjective estimation of the activity. Findings presented an odds ratio of 0,963 and therefore an estimation of a higher subjective fitlevel decreases the odds of obtaining the weight reduction goal. These data implicated that the self-estimation often differs from the reality.
The dependent variable of weight reduction of the binary logistic regression model was the reference value of $0.5 \mathrm{~kg}$ each week [28]. This goal of $0.5 \mathrm{~kg}$ weight reduction was more easily achieved for higher obese individuals. At present, there exists only a relative weight reduction reference value for long-term maintenance. So, it will be more important to find cutoff points of relative weight reduction for an inpatient therapy.

Further investigation is necessary to understand and to identify the factors which will demonstrate the effectiveness of a successful long-term weight loss of a nondiet program for participants with a BMI $>40 \mathrm{~kg} / \mathrm{m}^{2}$. Information of the drop-outs why they do not visit the out-patient followup care should be included.

Future studies should have a control group for comparison of the progression of the increasing problem of obesity. Standardized measures and also the inclusion of objective parameters, particularly of activities to check the self-estimation of fitness against reality, would be involved.

Findings of this study demonstrated that the primary outcome should not be only the weight reduction but rather the benefits of lifestyle modification [9] and their increasing quality of life. Also the emotional regulation of food intake, because this is often the problem for long-term behaviour modification, must be included.

\section{Acknowledgments}

This study was supported by Psychosomatisches Zentrum Waldviertel (PSZW) Eggenburg and Eggenburg Institute for Complex Systems, Health and Neuroscience (EICoN). 


\section{References}

[1] K. M. Flegal, M. D. Carroll, R. J. Kuczmarski, and C. L. Johnson, "Overweight and obesity in the United States: prevalence and trends, 1960-1994," International Journal of Obesity, vol. 22, no. 1, pp. 39-47, 1998.

[2] C. L. Ogden, M. D. Carroll, L. R. Curtin, M. A. McDowell, C. J. Tabak, and K. M. Flegal, "Prevalence of overweight and obesity in the United States, 1999-2004," Journal of the American Medical Association, vol. 295, no. 13, pp. 1549-1555, 2006.

[3] R. Ehrsam, S. Stoffel, G. Mensink, and T. Melges, "Overweight and obesity in the USA, Germany, Austria and Switzerland," Deutsche Zeitschrift fur Sportmedizin, vol. 55, no. 11, pp. 278285, 2004.

[4] J. O. Hill, "Understanding and addressing the epidemic of obesity: an energy balance perspective," Endocrine Reviews, vol. 27, no. 7, pp. 750-761, 2006.

[5] T. Ellrott and V. Pudel, Adipositastherapie. Aktuelle Perspektiven, Thieme, Stuttgart, Germany, 2nd edition, 1998.

[6] NHLBI National Institutes of Health, National Heart, Lung and Blood Institute, "Clinical guidelines on the identification, evaluation and treatment of overweight and obesity in adults," The Evidence Report 98-4083, NIH National Institutes of Health, 1998.

[7] H. Hauner, G. Buchholz, A. Hamann et al., Prävention und Therapie der Adipositas. Evidenzbasierte Leitlinie Version 2007. Deutsche Adipositasgesellschaft, Deutsche DiabetesGesellschaft, Deutsche Gesellschaft für Ernährung, Deutsche Gesellschaft für Ernährungsmedizin (Hrsg.), 2007.

[8] W. C. Miller, D. M. Koceja, and E. J. Hamilton, "A metaanalysis of the past 25 years of weight loss research using diet, exercise or diet plus exercise intervention," International Journal of Obesity, vol. 21, no. 10, pp. 941-947, 1997.

[9] V. A. Catenacci and H. R. Wyatt, "The role of physical activity in producing and maintaining weight loss," Nature Clinical Practice Endocrinology and Metabolism, vol. 3, no. 7, pp. 518529, 2007.

[10] J. M. Jakicic, "The effect of physical activity on body weight," Obesity, vol. 17, no. 3, pp. S34-S38, 2009.

[11] J. M. Jakicic, B. H. Marcus, K. I. Gallagher, M. Napolitano, and W. Lang, "Effect of exercise duration and intensity on weight loss in overweight, sedentary women: a randomized trial," Journal of the American Medical Association, vol. 290, no. 10, pp. 1323-1330, 2003.

[12] S. N. Blair, M. J. LaMonte, and M. Z. Nichaman, "The evolution of physical activity recommendations: how much is enough?" The American journal of clinical nutrition, vol. 79, no. 5, pp. 913s-920s, 2004.

[13] D. F. Tate, R. W. Jeffery, N. E. Sherwood, and R. R. Wing, "Long-term weight losses associated with prescription of higher physical activity goals. Are higher levels of physical activity protective against weight regain?" American Journal of Clinical Nutrition, vol. 85, no. 4, pp. 954-959, 2007.

[14] D. A. Schöller, K. Shay, and R. F. Kushner, "How much physical activity is needed to minimize weight gain in previously obese women?" American Journal of Clinical Nutrition, vol. 66, no. 3, pp. 551-556, 1997.

[15] K. M. Ross, V. A. Milsom, K. A. Rickel et al., "The contributions of weight loss and increased physical fitness to improvements in health-related quality of life," Eating Behaviors, vol. 10, no. 2, pp. 84-88, 2009.

[16] D. J. Yankura, M. B. Conroy, R. Hess, K. K. Pettee, L. H. Kuller, and A. M. Kriska, "Weight regain and health-related quality of life in postmenopausal women," Obesity, vol. 16, no. 10, pp. 2259-2265, 2008.

[17] B. Blissmer, D. Riebe, G. Dye, L. Ruggiero, G. Greene, and M. Caldwell, "Health-related quality of life following a clinical weight loss intervention among overweight and obese adults: intervention and 24 month follow-up effects," Health and Quality of Life Outcomes, vol. 4, article 43, 2006.

[18] K. R. Fontaine, I. Barofsky, R. E. Andersen et al., "Impact of weight loss on health-related quality of life," Quality of Life Research, vol. 8, no. 3, pp. 275-277, 1999.

[19] J. M. Rippe, J. M. Price, S. A. Hess et al., "Improved psychological well-being, quality of life, and health practices in moderately overweight women participating in a 12 -week structured weight loss program," Obesity Research, vol. 6, no. 3, pp. 208-218, 1998.

[20] B. Knechtle, "Endurance training, fat oxidation and body weight control," Schweizerische Zeitschrift fur Sportmedizin und Sporttraumatologie, vol. 50, no. 4, pp. 169-173, 2002.

[21] T. Ellrott, in Medzinische Behandlung, Medikamente und chirurgische Maßnahmen, F. Petermann and V. Pudel, Eds., pp. 183-206, Hogrefe, Seattle, Wash, USA, 2003.

[22] S. Pagoto, J. S. Bodenlos, L. Kantor, M. Gitkind, C. Curtin, and Y. Ma, "Association of major depression and binge eating disorder with weight loss in a clinical setting," Obesity, vol. 15, no. 11, pp. 2557-2559, 2007.

[23] K. L. Schneider, J. S. Bodenlos, Y. Ma et al., "Design and methods for a randomized clinical trial treating comorbid obesity and major depressive disorder," BMC Psychiatry, vol. 8 , article 77, 2008.

[24] S. Herpertz and W. Senf, "Psychotherapie der adipositas," Deutsch Ärzteblatt, vol. 6, pp. 269-274, 2003.

[25] M. Bullinger and I. Kirchberger, Der SF36-Fragebogen zur Erfassung des Gesundheitszustandes, Hogrefe, Göttingen, Germany, 1998.

[26] G. H. Franke, Symptom-Checkliste von L. R. DerogatisDeutsche Version (SCL-90-R), Beltz Test, Göttingen, Germany, 2002.

[27] V. Pudel and J. Westenhöfer, Fragebogen zum Essverhalten (FEV)-Handanweisung, Hogrefe, Göttingen, Germany, 1989.

[28] I. Kiefer, M. Kunze, and R. Schoberberger, Schlank ohne Diät. Motivation, Ernährung, Bewegung, Verhalten, Kneipp, Leoben, Wien, 2006.

[29] M. J. Franz, J. J. VanWormer, A. L. Crain et al., "Weight-loss outcomes: a systematic review and meta-analysis of weightloss clinical trials with a minimum 1-year follow-up," Journal of the American Dietetic Association, vol. 107, no. 10, pp. 1755$1767,2007$.

[30] J. Ogden, "The correlates of long-term weight loss: a group comparison study of obesity," International Journal of Obesity, vol. 24, no. 8, pp. 1018-1025, 2000.

[31] S. Carroll, E. Borkoles, and R. Polman, "Short-term effects of a non-dieting lifestyle intervention program on weight management, fitness, metabolic risk, and psychological wellbeing in obese premenopausal females with the metabolic syndrome," Applied Physiology, Nutrition and Metabolism, vol. 32, no. 1, pp. 125-142, 2007.

[32] M. De Zwaan, I. Petersen, M. Kaerber et al., "Obesity and quality of life: a controlled study of normal-weight and obese individuals," Psychosomatics, vol. 50, no. 5, pp. 474-482, 2009.

[33] B. H. Goodpaster, J. P. DeLany, A. D. Otto et al., "Effects of diet and physical activity interventions on weight loss and cardiometabolic risk factors in severely obese adults: a randomized trial," Journal of the American Medical Association, vol. 304, no. 16, pp. 1795-1802, 2010. 
[34] S. Nammi, S. Koka, K. M. Chinnala, and K. M. Boini, "Obesity: an overview on its current perspectives and treatment options," Nutrition Journal, vol. 3, article 3, 2004.

[35] R. R. Wing and S. Phelan, "Long-term weight loss maintenance," The American Journal of Clinical Nutrition, vol. 82, no. 1, pp. 222S-225S, 2005.

[36] C. Galani and H. Schneider, "Prevention and treatment of obesity with lifestyle interventions: review and meta-analysis," International Journal of Public Health, vol. 52, no. 6, pp. 348359, 2007.

[37] M. Beutel, R. Thiede, J. Wiltink, and I. Sobez, "Effectiveness of behavioral and psychodynamic in-patient treatment of severe obesity - First results from a randomized study," International Journal of Obesity, vol. 25, no. 1, pp. S96-S98, 2001. 


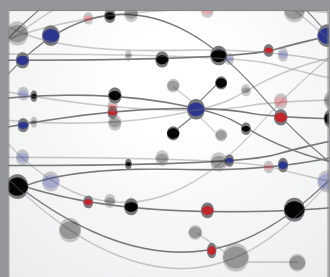

The Scientific World Journal
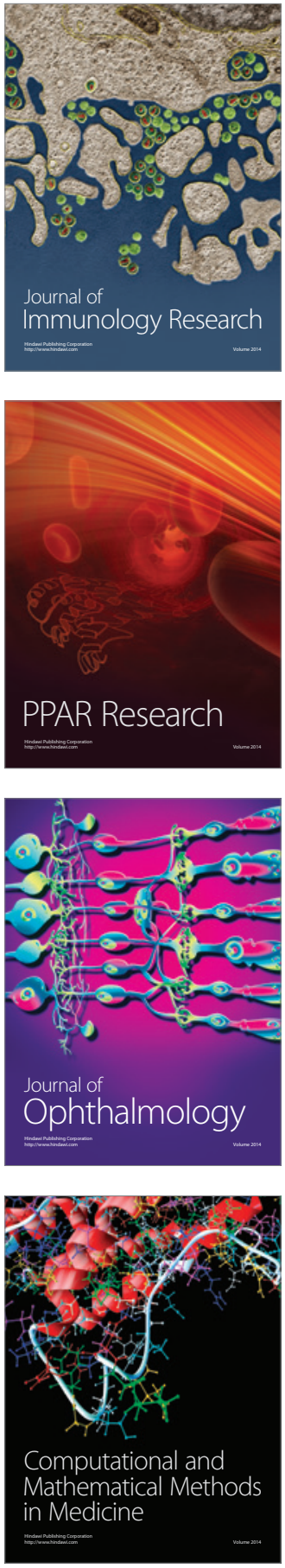

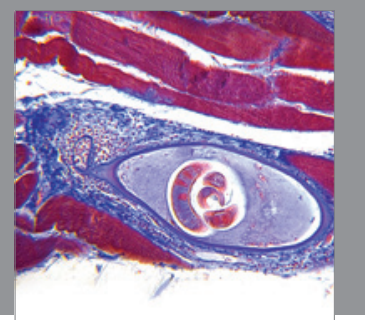

Gastroenterology

Research and Practice
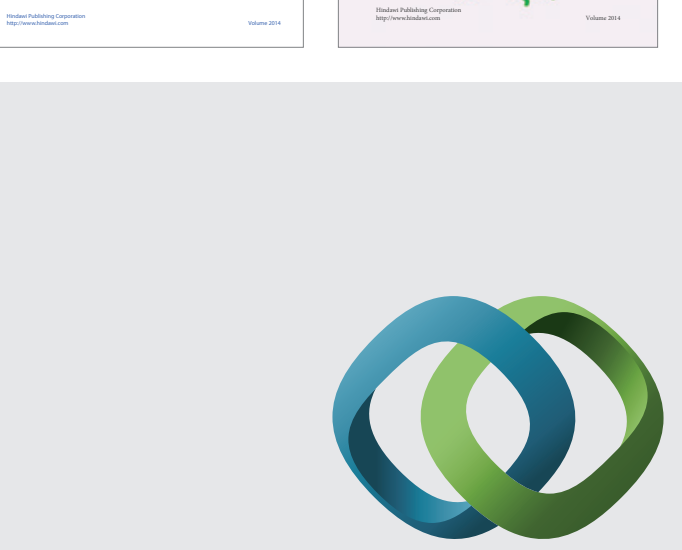

\section{Hindawi}

Submit your manuscripts at

http://www.hindawi.com
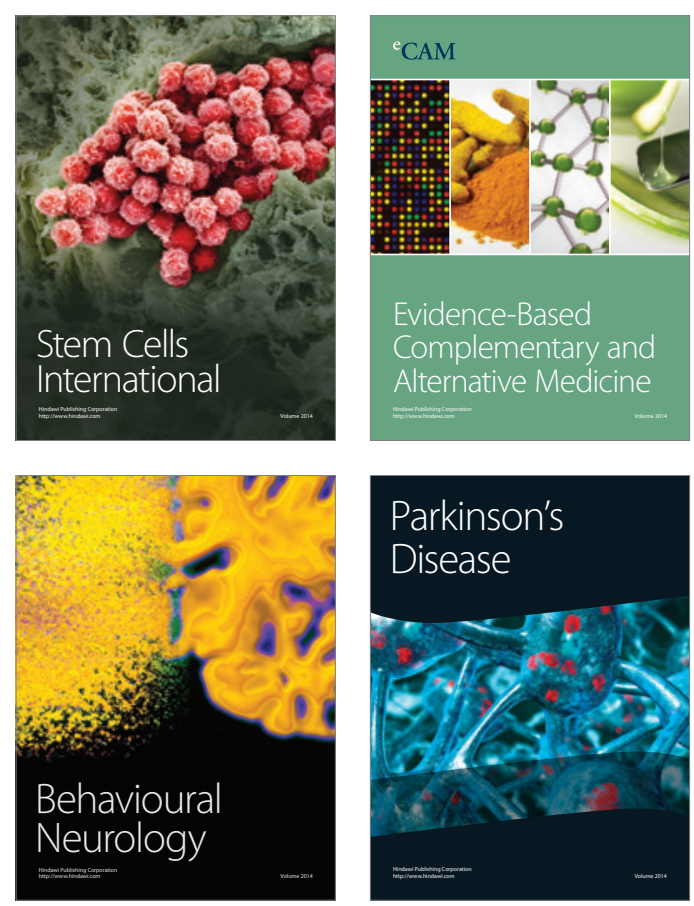

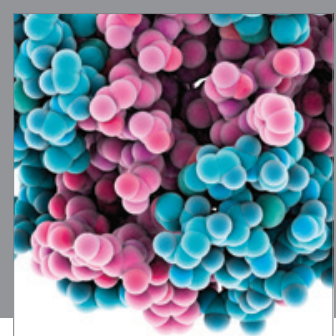

Journal of
Diabetes Research

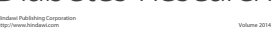

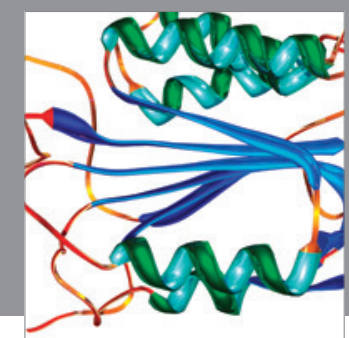

Disease Markers
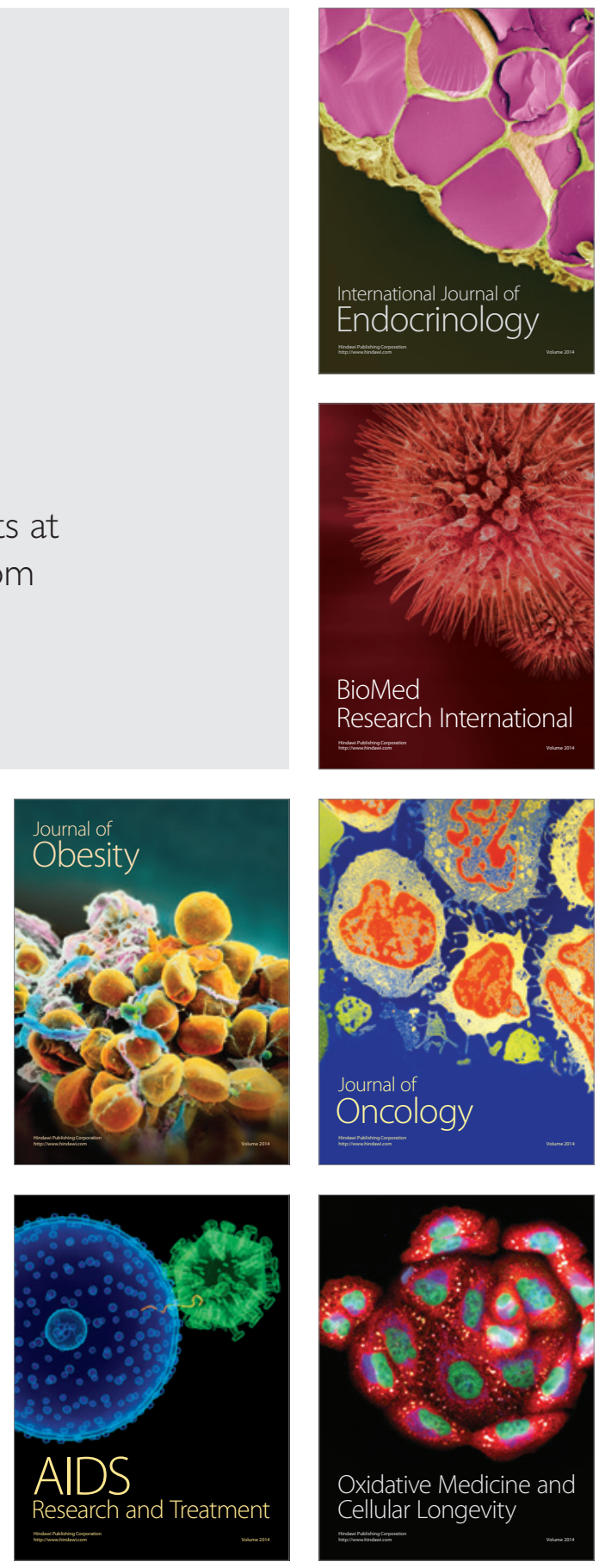